César Omar Mascorro Ibarra 


\section{El arte moderno en relación con la noción de arte en Schopenhauer}

\section{Introducción}

Comenzamos con una cuestión general: ¿puede el arte moderno ser entendido como una vía de salvación como lo señala Schopenhauer?

Con el apoyo de varios textos, como los de Arthur C. Danto, Después del fin del arte: El arte contemporáneo y el linde de la historia, se contrastará lo que se considera como arte moderno contextualizándolo a la idea de Arthur Schopenhauer expresada en su libro El mundo como voluntad y representación. Arthur Danto explica y ejemplifica los conceptos moderno, contemporáneo y posmoderno, que se vuelven bastante importantes pues son el apoyo para lograr contrastar el texto de Schopenhauer y saber si el arte moderno puede ser vía de salvación. También se hace uso de Walter Benjamin quien, en el texto La obra de arte en la época de su reproductibilidad técnica, trata sobre diversas cuestiones que se presentan en las obras artísticas (pinturas principalmente) y que poco a poco van tomando importancia en el trabajo, pues se maneja un concepto al que se recurre mucho y es muy importante: el de arte reflexivo. Es importante porque permite distinguir entre los tipos de arte que ha habido en las diferentes épocas.

\section{Schopenhauer y Danto}

La mejor obra de la juventud de Arthur Schopenhauer habla de tres temas de importancia trascendental, de los cuales se retomarán dos (ético y estético), uno de manera superficial (ético) y el otro va a ser el tema central, y es aquel donde habla del arte. 
Schopenhauer habla sobre el deseo que tiene el hombre y cómo éste, poco a poco, se convierte en dolor; algo que él destaca es que el hombre, por naturaleza, no tiene dicho deseo, sino que lo va a tener cuando sea corrompido por la voluntad del mundo (noúmeno). Una de las formas que este filósofo propone para liberarse de esa cadena o atadura a la corrupción, dada por la voluntad, es a través del arte, ya que el arte le ayudará al individuo (corrompido) a hacer un ejercicio reflexivo sobre la realidad en la que vive. No obstante, no es la única forma que hay para librarse de esta corrupción, otra es el ascetismo y ésta forma se podría decir que es la última, pues Schopenhauer afirma que el ascetismo es la verdadera forma de alejarse de la voluntad, ya que ésta lo único que hace es desear $y$, con esos deseos, causa sufrimiento a los hombres; el ascetismo es, entonces, solamente vivir con lo necesario.

Así pues, retomando lo que dijo Schopenhauer acerca del arte (como liberador del sufrimiento) y haciendo uso de los términos: contemporáneo, moderno y posmoderno que Danto da en su texto Después del fin del arte: El arte contemporáneo y el linde de la bistona; es como lograremos diferenciar el arte y las corrientes que surgieron en estas épocas (contemporáneas y modernas).

La primera definición que da es sobre el término contemporáneo, que en sus propias palabras argumentar como:

Contemporáneo. La diferencia es que ya no hay un plano diferente para distinguir realidades artísticas, ni esas realidades son tan distantes entre sí. Esto se debe a que la percepción básica del espíritu contemporáneo se formó sobre el principio de un museo en donde todo arte tiene su propio lugar, donde no hay ningún criterio a priori acerca de cómo el arte deba verse, y donde no hay un relato al que los contenidos del museo se deban ajustar. ${ }^{1}$

En su definición, Danto afirma que en el arte contemporáneo no hay mejores o peores obras, sino sólo diferentes; lo cual hace que, en caso de que exista un orden de colocación en los museos, si se rompe con este sistema, se podría decir que se va a crear uno donde todo aquello que en su espíritu sea arte va a ser valorado y apreciado por sí mismo.

1 Danto C. Arthur, Después del fin del arte: El arte contemporáneo y el linde de la bistoria, p, 28. 
El siguiente concepto que define es el de moderno; se marca como diferencia que en éste hay una conciencia mayor que en lo que se considera como contemporáneo, además de que es lo que se hace en ese momento.

Moderno. El modernismo está marcado por el ascenso a un nuevo nivel de conciencia, reflejado en la pintura como un tipo de discontinuidad, como si acentuar la representación mimética se hubiera vuelto menos importante que otro tipo de reflexión sobre los sentidos y los métodos de la representación.

«Moderno» no es simplemente un concepto temporal que significa «lo más reciente», tampoco «contemporáneo» es un término meramente temporal que significa cualquier cosa que tenga lugar en el presente. ${ }^{2}$

Pero no se queda con esas dos definiciones, pues entrega una tercera que se vuelve de mucha importancia, ya que se puede decir que es un punto medio entre lo que ya se había dicho. Es en la definición de lo posmoderno donde se halla los elementos que entran aquí y que posiblemente se consideraban dentro de lo moderno y contemporáneo.

«Posmoderno». Este término muestra por sí mismo la relativa debilidad del término «contemporáneo» como denominación de un estilo por parecerse más a un mero término temporal. Pero quizá "posmoderno» sea un término demasiado fuerte, $y$ que identifica sólo a un sector del arte contemporáneo. «Elementos que son híbridos más que "puros", comprometidos más que "claros", "ambiguos" más que "articulados", perversos y también "interesantes" ». Se podrían ordenar las obras de arte utilizando esta fórmula, y probablemente se obtendría una lista coherente y homogénea de obras posmodernas. ${ }^{3}$

Según lo que Danto expresa en las definiciones vistas, que se tomaron en cuenta, no todo es arte, pues en su libro El abuso de la belleza hace una severa crítica a lo que posteriormente muchos le llamarían "arte". Afirma que en el surgimiento de estas nuevas

2 Ibidem p. 32.

3 Ibidem p. 35. 
formas de arte se llega a abusar de las cuestiones estéticas de las cosas hasta alcanzar un punto donde cualquier objeto puede ser considerado "arte". Para Danto, más que ser arte como tal, será considerado como la forma más vulgar y baja del arte, ya que este nuevo arte no entra en ninguna de las definiciones que ya se tenían (pintura, escultura, etc.); por ello, a este nuevo arte que se forma tomando los objetos cotidianos con el fin de hacerlos ver de una manera estética o haciendo que a partir de ellos se dé una reflexión (como lo que hicieron los movimientos vanguardistas en su momento), Danto lo considera como una mofa al arte.

Los elementos que Danto considera son aquellos como un collage o bibridación (sin llegar a un abuso de las formas) en el arte. Esto puede ser una mezcla de moderno y contemporáneo; por la técnica entra en una clasificación, pero por el contenido, en otra, lo que al final dificulta saber si pertenece a lo moderno o a lo contemporáneo. Esa dificultad es lo que hace posible la definición de posmodernidad en el arte.

Tomando esto en cuenta, se puede facilitar una contextualización de lo que Schopenhauer afirma acerca del arte y si las definiciones culturales $y / o$ técnicas, que nacen en una cultura y son promovidas por esta misma son capaces de darle una salvación al ser humano. Pero, ¿qué es lo que dice este autor?, lo que señala es lo siguiente:

En el modo de consideración estético hemos hallado dos elementos inseparables: el conocimiento del objeto, no como cosa individual sino como idea platónica, como forma persistente de toda esa especie de cosas; y luego la autoconciencia del cognoscente no como individuo sino como puro e involuntario sujeto del conocimiento. La condición para que esos dos elementos aparecieran siempre unidos era el abandono de la forma de conocimiento ligada al principio de razón, la cual es, en cambio, la única apta para el servicio de la voluntad así como para la ciencia. Veremos que también el placer suscitado por la contemplación de lo bello surge de esos dos elementos, más de uno o de otro según sea el objeto de la contemplación estética. ${ }^{4}$

4 Schopenhauer, Arthur, El mundo como voluntad y representación, p, 117, p. 38. 
Lo primero que se debe tomar en cuenta es que Schopenhauer habla de lo estético, ya que forma parte del arte, de modo que aquello que es estéticamente agradable, es lo que nos va a llamar la atención y que además nos va liberar del deseo, que tarde o temprano se convertirá en un dolor, del que vamos a buscar librarnos. Pero no es una dolencia corporal; se podría decir que se trata de una dolencia un tanto más psicológica ya que proviene de un deseo, originado por la corrupción que se da a través de lo que Schopenhauer afirma que es la voluntad. La voluntad, por su parte, se va a encontrar al llegar a quitar el velo de la realidad, pues ella se esconde detrás de este velo. También habla sobre la naturaleza de dicha voluntad: esta naturaleza es la del deseo, pues la voluntad no hace otra cosa que no sea desear y desearse a sí misma.

El hombre por naturaleza puede ser susceptible a esa voluntad, mas no está en su naturaleza. Cuando el hombre es corrompido o la voluntad que se esconde detrás de la realidad ha logrado transmitir su naturaleza en éste, el hombre vive deseando constantemente y si por alguna razón llegase a satisfacer el deseo por el que sufre en un determinado momento, ese individuo llegaría a hartarse rápidamente de eso, de modo que volvería a desear y, así, a sufrir.

Como ya se dijo, Schopenhauer considera dos posibles formas de alejarse de esta voluntad y llevar una mejor vida: el arte y el ascetismo. Con la primera, la cercanía al arte, cuando el hombre ya está corrompido y lo que busca es dejar a un lado el dolor recurre a la apreciación del arte para poder olvidar esos deseos (sufrimiento), lo que consigue apreciando el arte y reflexionado acerca del mismo.

La otra forma es el ascetismo, que prácticamente consiste en vivir sólo con lo necesario, no necesitar lujos y con esto estar libre de esa voluntad, porque con el ascetismo sólo se va a tener lo que se necesite para vivir.

Schopenhauer menciona una palabra muy importante: razón. Si se busca esa palabra en las definiciones de Danto, se puede encontrar en la parte donde habla de lo moderno, mas no como razón, sino como un nivel de conciencia que lleva al ser humano a reflexionar, a ser más crítico.

Esto ayudaría a pensar que Schopenhauer se refería a lo que en su contexto social y cultural se consideraba como moderno en el arte y que era precisamente esto lo que el autor estimaba que se debía apreciar. ¿Por qué?: sencillo, pues como todo aquello que era anterior no reflejaba otra cosa que no fuera una divinidad (en caso de la Edad 
Media), o bien la representación de batallas o guerras, ya sea de seres humanos o entre divinidades (esto para una época como la de los griegos), entonces, el arte sólo era mera imitación de lo que se vivía.

Así que es posible pensar que cuando llega un movimiento modernista a la cultura, se lleva a cabo toda una revolución de lo que se hacía y se pensaba como arte. La creación de esto tenía un pensamiento, una crítica e incluso un mensaje que se buscaba hacer llegar a las personas.

La variación de la cultura se da gracias a la época en la que se encuentra y también a sus subculturas; estas últimas, poco a poco se vuelven más importantes e incluso llegan a colocarse a la misma altura que las demás. Claro que esto se logra poco a poco, ya que no es tan fácil que surja y se desollare un cambio en la época, pues cuando ocurre es cuando hay nuevos deseos y nuevas necesidades.

Al florecer esto, nace una nueva forma de arte moderno, como los movimientos que hasta ahora se han dado; entre los cuales se hallan los siguientes, considerados vanguardias.

Dadaísmo. Surge para oponerse al arte establecido. Es un movimiento que desde el nombre se muestra revolucionario, pues al nacer como movimiento afirma que el "da-da" es la más clara representación. Pero, ¿qué buscaba este movimiento?: humillar las técnicas establecidas.

Surrealismo. Es un movimiento que pretendía hacer uso del inconsciente para la creación de nuevas obras.

Cubismo. En éste se buscaba hacer desaparecer la perspectiva tradicional de los anteriores movimientos que se encontraban a la vanguardia.

Podemos encontrar ejemplos de estas tres corrientes, en cualquier historia del arte contemporánea. En general, las corrientes vanguardistas que nacieron en el siglo $\mathrm{XX}$ surgieron para proponer un arte completamente reflexivo para aquel que lo apreciara (así como para quien lo hiciera).

Y si bien hubo muchos movimientos, los mencionados son los que más demostraron ser revolucionarios, incluso hasta modernistas, por su pensamiento crítico. En consecuencia, con la llegada de las vanguardias, tuvo lugar una adaptación de la cultura hacia estas propuestas, que en su tiempo fueron revolucionarias.

Gracias a esa adaptación, ha persistido una constante búsqueda del arte con un cariz moderno. No obstante, cada vez se vuelve más difícil encontrar esa característica en él, pues cada vez 
más, también, el arte se convierte en una reproducción de obras hechas y se juzga como sin bases un pensamiento crítico, lo que hace más difícil crear un medio adecuado para la liberación del sufrimiento. De modo que estar en una constante actualización del concepto de arte no le traería ningún beneficio a la humanidad.

Si bien ya se ha dicho que las vanguardias son arte reflexivo, no escapan de lo que Walter Benjamin, en su texto El arte en su época de reproductividad, llegó a definir como un aura y esta aura, para el autor, es dos cosas:

- el ámbito entero de la autenticidad, que se sustrae a la reproductibilidad técnica ${ }^{5}$

- la manifestación irrepetible de una lejanía (por cercana que pueda estar) ${ }^{6}$

Con esto se refiere a que no importa cuán innovador o revolucionario sea un estilo que se presente, ya que de cualquier modo carecerá de originalidad, pues en sus obras se estarán reproduciendo dos cosas: la realidad (segundo punto) y, en cierta medida, las técnicas anteriores al artista que las emplea.

\section{Conclusión}

En las vanguardias se ha logrado observar muchas técnicas, y aunque fueron una revolución artística para su época, siguieron respetando o conservando algunos de los cánones estéticos que rodeaban la pintura, pero también rompieron algunos de éstos.

Aunque no tan claramente como los griegos o en el realismo artístico, las vanguardias llegaron a representar la realidad, aunque fuera exótica para unos y un tanto extraña para otros. Lo cierto es que la suya fue una nueva visión de la realidad.

5 Benjamín, Walter, La obra de arte en la época de su reproductibilidad técnica, p. 21.

6 Idem p. 24. 